Página inicial: 495 - Página final: 513

TIPO DE ARTÍCULO: de Investigación

\title{
LAS PRÁCTICAS COMUNITARIAS DE JUSTICIA LOCAL EN LA SIERRA DE LA MACARENA. EL PLURALISMO JURÍDICO DE CARA A LA RECONSTRUCCIÓN DEL PAÍS EN EL POST CONFLICTO COLOMBIANO. ${ }^{1}$
}

\begin{abstract}
COMMUNITY PRACTICES OF THE LOCAL JUSTICE IN "LA SIERRA DE LA MACARENA." THE JURIDICAL PLURALISM WITH AN EYE TO THE COUNTRY RECONSTRUCTION IN THE COLOMBIAN POST CONFLICT.
\end{abstract}

\author{
RECIBIDO: ENERO 2015 REVISADO: ABRIL 2015 ACEPTADO: 2 DE MAYO DE 2015
}

Por: Nicolás Espinosa Menéndez. ${ }^{1}$

\section{RESUMEN:}

Este artículo presenta una caracterización de las instancias comunitarias de resolución de conflictos que desde hace más de una década son las encargadas de tramitar conflictos en la región de la Sierra de La Macarena, Colombia. El texto propone que la Justicia Local de esta región integra una serie de condiciones sociales que no solo podrán apoyar la transición sociopolítica de la región, en caso de llegarse a un acuerdo entre el estado colombiano y la insurgencia, sino que además vale la pena su sostenimiento en el tiempo por la apuesta de paz que representan. Para tal efecto, el artículo presenta un balance analítico del trabajo adelantado por Comités de Conciliación a partir de su caracterización y ofrece elementos claves para comprender la lógica y naturaleza de la justicia comunitaria de La Macarena.

\section{PALABRAS CLAVE:}

Pluralismo Jurídico, Derecho Crítico, Conflicto Armado Colombiano, Post Conflicto, justicia comunitaria.

\begin{abstract}
:
This article presents a characterization of the community agencies in the resolution of conflicts, which over one decade are in charge of dealing with conflicts in the region of the Sierra de La Macarena, Colombia. The text proposes that the local Justice in this region integrates a series of social conditions that not only be able to support the socio-political transition of the region, in case of reaching an agreement between the Colombian State and the insurgency, but it is also worth supporting it in time for the bet of peace that they represent. For this purpose, the article introduces an analytical balance of the work carried out by the Conciliation Committees from its characterization and it provides key elements to understand the logic and nature of the community justice in La Macarena.
\end{abstract}

\section{KEY WORDS:}

Legal pluralism, critical right, Colombian armed conflict, post-conflict, community justice.

\footnotetext{
${ }^{1}$ Sociólogo. PhD (c) Antropología, Universidad de Arizona. Docente-Investigador de la Facultad de Derecho, de la Universidad de San Buenaventura, Medellin-Colombia. Contacto: nicolas@email.arizona.edu, nicolas.espinosa@, usbmed.edu.co
} 


\section{Introducción.}

Este artículo recoge apartes de un trabajo que desde hace más de una década he realizado sobre el devenir de la Justicia Local en la Sierra de La Macarena. Mi etnografia la empecé allí durante los dias del fallido proceso de paz entre el Gobierno Pastrana y las Farc-Ep (tiempo en que la región fue desmilitarizada y reconocida como "zona de despeje", 1998-2002), y continua hoy día, cuando sobre la región se ha vivido una intensa política contrainsurgente y se sigue con atención y expectativa el actual proceso de paz.

El objetivo de mi trabajo en La Macarena tiene que ver con los retos que le esperan a la región de llegarse a un acuerdo entre el estado y la insurgencia, en particular sobre las condiciones sociales para adecuar la transición sociopolítica de la región (la resolución comunitaria de conflictos, uno de sus aspectos esenciales), y el papel que le espera a las organizaciones comunitarias como actores centrales para articular las políticas e iniciativas de transición. Este objetivo, aplazado a fuerza de las circunstancias desde 2002, encuentra un momento histórico apropiado para su desarrollo y me permite formular nuevas hipótesis. Por ello, este texto lo he preparado como soporte de una reciente investigación con la que me propongo dar un testimonio analítico de prácticas locales y comunitarias de resolución conflictos. En este texto me concentro especialmente en el trabajo de los Comités de Conciliación y algunas de sus condiciones y características.

Pero antes de detenerme en estos detalles, un poco de historia y un tanto de contexto sobre la zona pueden ser útiles para quién no tiene mayor referencia de esta región. La Sierra de La Macarena tiene como particularidad que alli se encuentran unas condiciones biológicas excepcionales, y una historia social muy especial. Como parte del Escudo Guyanés y encuentro de los ecosistemas Andinos, Orinocense y Amazónico, La Sierra de La Macarena es considerada Patrimonio de la Humanidad dada su importancia ecológica (Ruiz, 2003). Ubicada en el piedemonte amazónico colombiano, La Macarena es una zona de frontera agrícola poblada por familias campesinas expulsadas por distintas violencias en el país desde mediados del SXX, y atraídas por las posibilidades de tener tierra y prosperidad. En 1964, a orillas de sus ríos, fueron fundadas las Farc y si bien su territorio ha sido escenario privilegiado para el despliegue guerrillero y las políticas contrainsurgentes, allí se ha gestado una expresión territorial de autonomía comunitaria y campesina sobre la que se construyen algunos de los principales apartados del proceso de paz presente.

La transición será sin duda un reto cuya complejidad tiene que ver con la superación de la represión política y de la exclusión económica por medio del reconocimiento y apoyo a las formas de autogobierno y organización que -de manera creativa- han sido creadas en La Macarena como repuesta social al conflicto. Será pues, sobre las organizaciones campesinas, donde las apuestas de paz pueden encontrar un escenario idóneo para su desarrollo.

El propósito de este texto consiste, pues, en ofrecer elementos de comprensión sobre la justicia comunitaria de La Macarena. Este articulo corresponde a la presentación revisada y actualizada de mi experiencia de trabajo de campo en la región, con una perspectiva crítica que se enmarca en la propuesta del Pluralismo Jurídico (Wolkmer, 2003).La vasta multiplicidad de experiencias jurídicas que existen en la región y que el Pluralismo Jurídico permite reconocer, suponen un interesante desafio para la transición que se avecina: ¿cómo sostener las experiencias exitosas de resolución de conflictos, cómo superar el orden armado que ostenta la insurgencia, como relegitimar la institucionalidad estatal sin detrimento del respeto y promoción de la autonomía comunitaria? ¿Qué lecciones pueden ser aprendidas de La Macarena para contrastarlas con otras regiones, y viceversa? Mis preguntas se orientan tanto a institución del estado y las expresiones de la sociedad 
civil que se preocuparán por la transición, como a la plataforma política que recogerá la propuesta insurgente. Pero, en particular, se orienta a las comunidades campesinas que dan cuerpo a la organización social y comunitaria. Son estas organizaciones quienes tendrán que sostener los modelos de Justicia Comunitaria que han configurado como una institución para la sociedad campesina. Esto quiere decir que la Justicia Local tiene una tradición y trascendencia que puede ser pertinente conocer.

La historia de La Macarena da cuenta que con el pasar de los años la resolución de conflictos ha tomado formas diferentes y ha cumplido un distinto papel en la construcción de la región, pues cabe recordar que La Macarena fue una zona de colonización donde primero llego la gente y luego las instituciones. Una experiencia característica de este proceso es la Vereda El Socorro, una comunidad ubicada en el Guayabero Medio, cercana al casco urbano, en donde coexisten distintas historias de poblamiento y donde se han vivido todas las manifestaciones de violencia que han afectado la región. A mediados de los años 70 , los problemas de esta naciente comunidad eran poco frecuentes: los viejos y las viejas me han contado que alli las extensiones de las fincas evitaban la invasión de animales del vecino, la gente era poca, los problemas eran arreglados entre las partes y las regulaciones guerrilleras aún no se habian instaurado. Las desavenencias por linderos, el trazo de los caminos y el manejo del ganado aumentaron conforme nuevas familias colonas se establecieron en la región. El creciente proceso de poblamiento a finales de esa década, y la adopción del cultivo de coca como alternativa económica, coincidió con el aparecimiento de la guerrilla, quienes a finales de los años 70 llegaron a "poner orden" y a construir su proyecto insurgente.

La producción de la coca encontró en la guerrilla, pues, el agente preciso para su regulación: como cualquier otra producción campesina, es susceptible de ser objeto de conflicto entre vecinos. Pero como toda actividad ilegal, sus conflictos escapan al arbitrio del estado y tienden a ser muy violentos. La guerrilla, como consta en los testimonios recogidos por Alfredo Molano (Molano, 1999), apareció en las Selvas del Guaviare en una época en que la coca fue bonanza, el dinero corrió a montones y la muerte y violencia se dieron silvestres (Véanse los relatos "El retorno del tío Zabaleta" y "El desecho"). La Macarena, aunque no fue ajena a este conflicto, vivió con menor intensidad eso que Fernando Cubides caracterizara como "la práctica disolución de una ética de trabajo y una ética empresarial" (1989, p 331) que, dice el autor, "durante el periodo de la bonanza, encontró un paliativo...con las medidas coactivas de la guerrilla para restaurar la siembra de cultivos de subsistencia, refrenar el consumo de bazuco y las manifestaciones más virulentas" (Cúbides, 1989, p 331) . El orden guerrillero se imbricó con el naciente orden social al tomar forma en los manuales de convivencia, y al establecer un precario sistema de resolución de conflictos.

Pero la justicia local a no se agota en la coca, ni se remite exclusivamente a la guerrilla. La justicia local corresponde a un proceso histórico que involucra a los comités de colonos creados en los años 70, quienes establecieron las primeras normas de convivencia, normas que luego se reformularian con el posicionamiento de la coca (años 80), la consolidación de la guerrilla y sus regulaciones más allá de las normas de convivencia (años 90), el fortalecimiento de los comités de conciliación (años 2000) y las regulaciones socioambientales que las asociaciones campesinas han introducido en la región (2010-presente).

Esta Justicia Local la he definido como la suma de los criterios básicos (valores normativos), mecanismos (fórmulas consensuadas de arreglo), instancias y formas como la guerrilla y las comunidades campesinas, definen y resuelven conflictos de carácter comunitario (es decir, conflictos de convivencia campesina). Tal resolución se sustenta en una noción de justo comunitario, un constructo ético y moral que hace las veces del ethos básico, la "norma de normas" que le sostiene y que se define en términos del bien común conforme las prácticas 
y costumbres de la región. Si bien en trabajos anteriores he propuesto un modelo analítico que permite proponer el campo jurídico del otro derecho como alternativa para definir que, en efecto, allí existe otro derecho, en este artículo me propongo presentar cómo funciona y procede este Sistema Jurídico Local.

Para tal efecto en este artículo quiero exponer las principales condiciones y características del trabajo de los Comités de Conciliación. Pero antes, y en la siguiente sección, quiero presentar una serie de antecedentes de guerra y paz que han sido fundamentales para definir el papel que juega la justicia local en la configuración de autonomías comunitarias.

\section{Contexto reciente: de la zona de despeje (1998-2002) a la Habana (2012-presente).}

La perspectiva que puede tener la Justicia Comunitaria en la transición democrática de la región no es una discusión nueva, y encuentra un importante antecedente en un momento histórico particular: el proceso de paz de 1998 y la zona de despeje. Este hito definió desde entonces un discurso estatal sobre la región, refiriéndose como "El Caguán" a toda la zona de despeje, cuando esta denominación sólo existe allí para reconocer las riberas del Río Caguán. Tal estereotipo ha definido discursos académicos y políticos sobre la región que contribuyen a reproducir la marginalidad de las zonas de frontera. Al respecto Teófilo Vázquez -enfocándose específicamente, eso sí, en la región ribereña del Río Caguánencontró que:

Una revisión somera de bibliografia sobre el conflicto en la región da cuenta de la singular visión marginalizada que ha predominado sobre El Caguán. En efecto, la región se asocia con el control exclusivo de las FARC y con cultivos de coca, lo cual es atribuido a la ausencia de las instituciones estatales (Vázquez, 2014)

Así mismo, este hitó contribuyó a definir la forma que tomaría desde entonces las prácticas contrainsurgentes (enmarcadas en la "recuperación del territorio") y las formas de control guerrillero que se han ensañado contra las gentes de la zona. En este contexto es donde la Justicia Comunitaria puede ser concebida, y es una de las hipótesis de mi trabajo, como una respuesta social a la guerra: ha permitido a las comunidades ganar autonomía frente al estado y ante la guerrilla. Les ha exigido mejorar sus formas de autogobierno, y es una de las fuentes que les ha permitido plantear un orden social autónomo. En esta sección, ofreceré una breve lectura del reciente contexto de la región que permite reconocer la Justicia Local en los términos que he propuesto.

Al mediar el mes de enero de 2002, las perspectivas del proceso de paz de ese entonces aunque estaban en su momento más crítico- parecían aclararse. El cruce de comunicaciones entre las Farc y el Gobierno en aquellos días, con la mediación de la ONU, de manera aparente reencaminaban el proceso. Pero no fue así. La historia se ha encargado de demostrar que ni las Farc confiaban en el gobierno Pastrana (pues continuaron con sus perspectivas de crecimiento y expansión), ni el Gobierno Pastrana tenía intención alguna para llegar a un acuerdo (el Plan Colombia estableció como prioridad la reingeniería de la guerra contrainsurgente). Las versiones más extendidas sobre lo qué allí sucedió, aunque disímiles por su origen (crónicas periodísticas, discursos políticos, análisis académicos), tienen como lugar común que no necesariamente incorporan las versiones de los habitantes de la región (Caguán Vive, 2009)

La narrativa oficial vio en el despeje la capitulación del estado, el engaño de la guerrilla, la pérdida de la soberanía, y quizá lo más grave: la futilidad de una paz negociada. (Leal, 2006) .Durante $\mathrm{m}$ mi trabajo me he encontrado que ha sido muy poca la producción 
académica, y menos aún las lecturas oficiales capaces de dimensionar el despeje en sus justas proporciones (o por lo menos sin recurrir a los estereotipos y asociaciones fáciles entre marginalidad y criminalidad) (Caracol, 2002). Y si bien en términos académicos, la zona de despeje y la fallida negociación no parecieron ser fuente de mucho interés sobre su naturaleza, condiciones y consecuencias (Centro Nacional de Memoria Histórica CNMH, 2014) ,se destacan la lectura sociopolítica que hicieran Fernán González (quién situó "el despeje" en una perspectiva de largo plazo en la historia de la guerra y la paz, (González, 2002) y los trabajos detallados de Fernando Cubides quién desde la crónica sociológica nos introdujera en la zona antes del despeje, (Cubides, Crónica de un breve trabajo de campo en el área de despeje, 1998) sus condiciones sociopolíticas y condicionamientos de orden nacional, (Cubides \& Domínguez, Desplazados, migraciones internas y reestructuraciones territoriales, 1999), y desde el balance de los procesos de paz fallidos, (Cubides, Algunas consideraciones sobre los procesos de paz fallidos en Colombia (O de cómo inventar caisas creíbles), 2005). Desde otra perspectiva, (Agnew \& Oslender, 2010) tratan lo que fue la zona de despeje desde una lectura de las distintas territorialidades que actores no-estatales han construido en Colombia, lugares definidos por distintos regímenes de autoridad que se superponen en el país.

Sin embargo, "eso" que pasó durante la desmilitarización en la región, y la situación de reajuste institucional (en particular la forma como el estado ha hecho presencia alli, desde una retórica y práctica encausada dentro de un teatro de operaciones militares y contrainsurgentes) y de replanteamiento politico-militar de las Farc-Ep (mayor movilidad militar, distinta relación política con las comunidades), no ha sido objeto de mayor análisis.

Pero si ha sido tema recurrente, y con razón urgente, las denuncias sobre la crisis humanitaria que se vivió después del despeje. Los asesinatos sumarios y selectivos realizados por la guerrilla (Noticias del Llano, 2013), las detenciones masivas y ejecuciones extrajudiciales (Revista Semana, 2010) atribuidas a las Fuerzas Militares (TIEMPO, 2007), y las consecuencias que las recurrentes infracciones al DIH y DD.HH por parte de ambos grupos armados, han sido objeto de atención de parte de ONG`s de defensa de los DD.HH (Tercer Canal, 2010), personalidades políticas, instituciones estatales y, en particular, por las mismas comunidades.

A este respecto se ha abierto un nuevo escenario de indagación que sin duda resultará útil para el diseño de la transición: el afianzamiento de aquellas organizaciones comunitarias que en medio del conflicto han sido capaces de resistir y plantear respuestas al mismo. La estrategia de los Comités de DD.HH, la participación de organizaciones comunitarias en la Marca Patriótica (Fundación Paz y Reconciliación, 2014) (Ribon, 2014), la división territorial agendas locales y regionales fundamental de las ya históricas Juntas de Acción Comunal, ha sido una estrategia idónea y efectiva de auto-protección comunitaria.

Es claro: el contexto sociopolítico de la región es mucho más complejo que las líneas aquí expuestas. Sin embargo quiero señalar que a pesar de los fuertes impactos que ha tenido la guerra en la población, las Juntas de Acción Comunal se han sostenido y las experiencias de justicia comunitaria que yo encontrara en la región a comienzos de la década del 2000 aún permanecen. Los Comités de Conciliación han seguido trabajando, la justicia local ha sobrevivido y aún contribuye a la construcción del ethos comunitario (Ramírez, González, \& Espinosa, 2014) Puesto que la Justicia Local, además de hacer las veces de narrativa, implica una serie de elementos prácticos, los siguientes apartados tratarán sus lógicas y aplicaciones. 


\section{Los problemas comunitarios y su clasificación.}

El concepto de derecho en el que me apoyo establece que todo sistema jurídico posee un proceso regularizado para solucionar conflictos (Sousa Santos, 1991). Para el caso de La Macarena el rasgo más importante de dicho proceso es que según el contexto y el tipo de problema resulta pertinente acudir a la justicia del estado, o a la Justicia Local. Si se trata de la zona rural (espacio sobre el cual me enfocare en el artículo) ocasionalmente y muy rara vez se busca la participación de la inspección de policía.

Es así que cuando ocurre alguna desavenencia entre vecinos o vecinas la primera instancia para solucionar un conflicto menor (ya explicaré cuales son estos) debe ser el Comité de Conciliación. Hasta hace poco más de una década no era así, pues todo problema llegaba a manos de la guerrilla. El principal elemento que define las instancias a recurrir es el tipo de problemas que pueden ocurrir. A continuación expongo una tipología comprensiva al respecto.

El lenguaje común campesino reconoce todo conflicto comunitario como un "problema". Estos conflictos se diferencian entre "problemas menores", donde la Junta puede intervenir con autonomía y sin necesidad de recurrir a la guerrilla o a las figuras jurídicas oficiales, y los "problemas graves" y/o "delitos" que son exclusivos para ser arreglados por la guerrilla o ante las instancias del derecho oficial. ¿Cuáles son los problemas graves? Una campesina me comentó que

Doña Támara: Los problemas mayores son los que se salen de las manos del Comité. Que ya, por decir algo, un ahogado, una matanza... qué se yo. Cosas supremamente delicadas. Porque un problema de linderos lo puede arreglar el Comité conciliador o la Junta. Un problema de un daño (una vaca que daña una cerca, por ejemplo): la misma cuestión. Qué se va uno a poner a andarle quitando por allá el tiempo a la guerrilla e involucrarlos en cosas que se pueden arreglar dentro la misma vereda.

Los problemas menores hacen referencia, pues, a los conflictos comunitarios que se generan por irrespetar alguna de las normas consuetudinarias campesinas (como puede ser, por ejemplo, que las cercas entre las fincas son una responsabilidad igual entre vecinos), en tanto que los problemas "graves" remiten, en primer lugar, a una idea de conflictos de dificil resolución algunos de los cuales pueden ser atendidos por los Comités. Los conflictos graves dan lugar a situaciones que el común de la gente en La Macarena reconoce como los delitos. Las graves violaciones a eso que el positivismo jurídico tradicional entiende como reglas primarias de obligación (el homicidio y los abusos sexuales, en particular), y por otro lado al desacato de las regulaciones impuestas por la guerrilla son consideradas como delitos. La siguiente es una caracterización de esta tipología:

Problemas menores: Estos problemas no cuentan con sanción alguna. Las formulas de arreglo, provengan del Comité o de la guerrilla si esta actuó como segunda instancia, contemplan indemnizaciones cuando hay daños a las propiedades, planes de pago cuando hay deudas no saldadas. Cuando la fórmula de arreglo acordada con el Comité no se cumple, o la decisión de la guerrilla no es obedecida, el cobro de multas aparece como una práctica común.

Problemas graves. Estos problemas son considerados así puesto que son objeto de sanciones, bien sea en calidad de multas, trabajos o una serie de respuesta sociales que suelen ser bastante creativas: en ocasiones las comunidades pueden decidir el tipo de sanción a imponen a los culpables (en el Sumapaz, por ejemplo han habido casos en donde 
las comunidades cesan toda comunicación con que la persona que trasgrede normas de la localidad) (Vera, 2006) . Entre los problemas graves que pueden ser resueltos por las comunidades se encuentran las ofensas, los chismes (rumores malintencionados sobre otra persona), las peleas, robos de poca monta.

Delitos. Son aquellos susceptibles de ser tratados y sancionados por la guerrilla y que implican una sanción fuerte, multas costosas, el destierro o la pena de muerte. La participación de las comunidades a la hora de definir los actos de alguien como un delito, y su posterior tratamiento como tal, es poco frecuente, por no decir excepcional. Pero tal excepcionalidad puede tomar la forma de asambleas comunitarias en donde la comunidad decide cómo proceder. En dos casos que me fueron narrados, el de un violador capturado por una comunidad del Guayabero bajo a mediados de los 90, y un crimen pasional ocurrido en el Yarí en 2010, la guerrilla reunió la comunidad y por votación se decidió la suerte de los acusados. El violador fue desterrado por unanimidad en asamblea, el asesino del amante de su esposa fue perdonado por el $70 \%$ de los votos escrutados. El desacato a las normas de la guerrilla, los robos productos de un asalto, y la captura de infiltrados, colaboradores o simpatizantes de la las fuerzas estatales son tratados exclusivamente por la guerrilla.

Y sea esta quizás, una de las situaciones más problemáticas de la región sobre la que tenga que llamar la atención: puesto que los acusados pocas veces tienen la oportunidad de defenderse, el ajusticiamiento de "infiltrados" es la principal estrategia que tiene la guerrilla para justificar la mayoría de sus crímenes contra los civiles, pues por lo general suelen deshumanizarlos como agentes del enemigo. Si bien el reconocimiento de las FarcEp sobre la afectación de sus acciones sobre los civiles fue considerada como histórica, no deja de ser autoexculpatoria. Según un comunicado emitido por esa guerrilla en abril de 2014: "No es política de las Farc atacar objetivos civiles, nunca en la historia de nuestra organización hemos planificado una acción militar para afectar a civiles". La Masacre de El Borugo en febrero de 2002, las ejecuciones sumarias de noviembre de 2002, el desplazamiento de la comunidad Pijao del Yaguara en 2004, entre otras tantas acciones realizadas en La Macarena, contradicen la pretensión de una ausencia de planificación.

A este respecto me ha resultado relevante identificar la superposición entre el derecho oficial, la racionalidad campesina y el orden guerrillero cuando la definición de delito se aplica a un tipo de violación normativa. Si bien una diferencia fundamental entre la justicia local y la justicia oficial se encuentra en el carácter sumario del orden guerrillero y las pretensiones de debido proceso del derecho oficial, un punto de encuentro fundamental entre ambos ordenes jurídicos se encentra en el reconocimiento campesino sobre la legitimidad de un agente externo -guerrilla o estado- como responsable de la atención de esos problemas que son considerados graves. En las regiones de La Macarena donde la guerrilla tiene una presencia activa, el comandante de turno se encarga de atender y dar solución a los problemas graves. En zonas cercanas al casco urbano la jurisdicción oficial es la encargada.

\section{Las instancias de resolución de conflictos.}

El sistema jurídico de La Macarena amplió sus horizontes en el momento en que la guerrilla se desprendió del arreglo de problemas, pues el trabajo de los comités para ese entonces era marginal y la oferta jurídica se limitaba a la guerrilla y en ocasiones (y solo para la gente cercana al pueblo, y los para determinados asuntos) a la inspección de policía o el juzgado. Desde 2001 -cuando el Bloque Oriental de las Farc-Ep determinó que ninguno de sus frentes debería involucrarse en la resolución de conflictos comunitarios; mis hipótesis al respecto 
circulan en torno a que la guerrilla había considerado que al atender los problemas de las comunidades podrían ganar antipatías entre las partes que no resultaran beneficiadas con sus decisiones. Así mismo, algunos comandantes (entre ellos Ivan Ríos, a quién entrevisté durante las negociaciones) consideraba que esta era una práctica paternalista que no contribuía al ejercicio del poder popular. Debo aclarar, eso sí, que a pesar de los problemas que pudiera representarles y a pesar de la concepción politica desde el liderazgo guerrillero, pasaron años hasta que la guerrilla definitivamente se desprendió del arreglo de problemas en la primera instancia. Los Comités son ejes centrales en la vida de las comunidades y desde ese entonces la oferta jurídica hace más compleja la trama de la región. Alli existe un entramado de instancias, procedimientos, fórmulas de arreglo, contextos sociopolíticos y situaciones de guerra y paz que no permiten establecer modelos lineales para comprender cuándo y por qué un conflicto es resuelto por la guerrilla, por el Comité de Conciliación o la justicia oficial.

Este juego dinámico entre prácticas campesinas, soberanías politicas y contextos sociopolíticos han permitido el establecimiento de una serie de sentidos prácticos-algunas de ellas implícitas en la vida diaria, a la manera de una gramática jurídica- relativos a la forma en que se debe proceder cuando hay un problema determinado. Según clásicos de la teoria jurídica, en particular (Hart, 1992) este tipo de normas son una serie de reglas de adjudicación. Dichas reglas, además de identificar a los individuos que pueden intervenir en el arreglo de problemas, definen también el procedimiento a seguir. Es decir, confieren potestades jurisdiccionales: cuándo, quiénes, y cómo. Esto quiere decir que en el sistema jurídico local define las instancias ante quiénes acudir según sea el problema.

La definición más importante ha sido aquella que encarga a los Comités actuar siempre en primera instancia cuando se presenta un "problema menor". Como se verá más adelante aquella orientación fue bastante relativa, pues a pesar de todo en muchos problemas la guerrilla siguió interviniendo pero sentó un precedente importante: los Comités de Conciliación de la Junta de acción comunal son la primera instancia para resolver un conflicto. En caso de no ser resuelto por ellos, el problema pasa a ser tratado por una asamblea de la Junta. Pero en cualquiera de los dos casos si no se llega a una solución se lleva a la guerrilla como "última instancia". Pero, en todo caso, ¿cómo funciona un comité de conciliación y cuáles son sus alcances? En la siguiente sección hablo sobre ello.

\section{El Comité de Conciliación: marco normativo y lugar comunitario.}

Toda Junta de Acción Comunal tiene, por estatutos, un Comité de Conciliación. El Comité tiene establecido trabajar por mantener las buenas relaciones entre los miembros de una Junta y ayudar a resolver sus diferencias en cuanto a la administración respecta, es decir, únicamente sobre los conflictos que se presenten en ella. Los manuales y la reglamentación sobre Juntas así entienden la función del Comité. Pero teniendo en cuenta que en muchas zonas rurales, La Macarena incluida, el Comité de Conciliación fue adoptado y adaptado por los campesinos como un órgano para resolver conflictos comunitarios, la reglamentación para las Juntas de Acción Comunal de 2002 estableció que los Comités, ahora llamados "Comités de Convivencia y Conciliación", pueden realizar "conciliaciones en equidad", donde las conciliaciones a que lleguen "prestan mérito ejecutivo y hacen tránsito a cosa juzgada",

"ARTICULO 46. Funciones de la Comisión de Convivencia y Conciliación. Corresponde a la Comisión de Convivencia y Conciliación: 
a) Construir y preservar la armonia en las relaciones interpersonales y colectivas dentro de la comunidad a partir del reconocimiento y respeto de la diversidad, para lograr el ambiente necesario que facilite su normal desarrollo.

b) Surtir la vía conciliatoria de todos los conflictos organizativos que surjan en el ámbito del correspondiente organismo de acción comunal.

c) Abocar, mediante procedimiento de conciliación en equidad los conflictos comunitarios que sean susceptibles de transacción, desistimiento, querella y conciliación.

PARAGRAFO 1. Las decisiones recogidas en actas de conciliación, prestarán mérito ejecutivo y transcienden a cosa juzgada. "LEY No. 7435 jun 2002

Me es interesante observar cómo el derecho oficial pretende reconocer el trabajo realizado por los Comités de Conciliación al integrarlo al ordenamiento jurídico nacional; pero más interesante resulta observar que dicho reconocimiento es inútil y no representa gran cosa para el trabajo de los Comités de Conciliación de La Macarena. El reconocimiento de las Juntas por parte del estado nunca ha sido un factor para legitimar el trabajo de los Comités, pues la labor desempeñada por ellos está al margen, precisamente, del estado. Nunca un Comité en La Macarena ha considerado recurrir donde un Juez en segunda instancia, ni mucho menos se ha apoyado en la fuerza pública, como amenaza del uso de la fuerza, para que sus decisiones "presten merito ejecutivo".

Ahora bien, que la conciliación de un conflicto gracias al trabajo de un Comité "preste merito ejecutivo y haga tránsito a cosa juzgada" es también irrelevante e improcedente para la realidad de la región, pues el derecho oficial -aunque tiene incidencia, no hay dudano tiene jurisdicción en la "otra orilla" de la Macarena, es decir, fuera del pueblo, en las zonas rurales. El reconocimiento entre las comunidades del trabajo de los Comités lo han dado los lazos de cohesión social que legitiman esta instancia comunitaria y el respaldo (según la vereda) que presta la guerrilla al trabajo de los Comités. Dicho respaldo consiste en delegar a los Comités la responsabilidad histórica que había asumido la guerrilla para resolver conflictos. La fórmula propuesta por Boaventura de Sousa Santos para comprender la naturaleza de un sistema jurídico no oficial a partir del distinto peso que tienen los elementos coerción/retórica/burocracia permite encontrar el papel aun preponderante que juega el elemento de coerción en la Justicia Local de la Macarena.

\section{Estrategias comunitarias para el tratamiento de sus conflictos.}

¿Qué hace un Comité de Conciliación? Prácticamente lo mismo que hace la guerrilla, es decir, resolver conflictos en las comunidades. Excepción hecha, claro está, de los "problemas mayores". Don Vicente alguna vez me comentó que la guerrilla le resolvió un conflicto "de la misma forma como el Comité pensó", es decir, ciñéndose al sentido común respetando el criterio de lo justo. Pero así los Comités hagan lo mismo que la guerrilla, no lo hacen de la misma forma ni cuentan con el mismo reconocimiento. La diferencia fundamental radica en que, a pesar que también la guerrilla usa en gran medida la retórica para dar fórmulas de arreglo y que en ocasiones busca conciliar las posiciones de los implicados, la guerrilla tiene el poder para "mandar" a hacer algo, pues encarna en sí misma la amenaza del uso de la fuerza y legitima gran parte de su acción por la "institucionalidad" que representa.

Algunos Comités, en cambio, acceden de forma indirecta a la amenaza del uso de la fuerza cuando les resulta imposible conciliar un problema y hay que recurrir a la guerrilla. Como no pueden mandar a hacer algo, el uso de la retórica y la argumentación es su fuerte y ello 
es algo que los caracteriza, legítima o deslegitima según el caso: algunas personas prefieren la fuerza de quien puede mandar, en tanto que otros prefieren arreglar por las buenas.

El carácter institucional que sostiene a un Comité se apoya en el grado de reconocimiento que tenga la comunidad hacia la Junta, en su composición democrática y experta, pues la gente espera que sus comités este integrados por personas aptas y pertinentes para desempeñar la labor, que conocen la región y su gente. Donde esto último es algo que resulta problemático, pues algunos campesinos dudan de la imparcialidad de las decisiones de los Comités porque sus miembros pueden ser conocidos de la contraparte. En cualquier caso, estas son discusiones más o menos recientes. Desde que el trabajo de los Comités se hizo una necesidad, algunas comunidades reconocieron que la responsabilidad de un Comité es grande. Eso llevó a que las Juntas se preocuparan por reforzarlos.

El referente de autoridad comunitaria más fuerte en una vereda es el Presidente de la Junta, por lo tanto en la mayoría de las ocasiones las personas con algún problema se dirigen donde el presidente y este puede o bien remitirlos con el Comité de Conciliación o ir a buscar a sus miembros para que se apersonen del problema. Por lo general el Presidente está al tanto de lo que hace el Comité, respetando su trabajo y no interfiriendo en él. En pocas veredas los Comités que funcionaban desde años atrás resolvian conflictos; esto sobre todo en las veredas renuentes a la guerrilla y las que están muy alejadas de las zonas de su influencia. Así que para mucha gente ha significado una novedad tener que acudir donde el Comité. Aun así, hay testimonios personas que dan cuenta que los Comités sí son pertinentes.

\section{El poder de los Comités: entre la conciliación y la decisión.}

Una confusión a que ha dado lugar la orientación guerrillera hacia los Comités ha sido cuál es el poder real de sus decisiones, pues aunque para muchos es claro que el Comité se define por el adjetivo que lo acompaña, "conciliador", por lo tanto "concilia". Pero también es cierto que en ocasiones "decide", es decir, no se limita a dar una fórmula de arreglo sino que también puede "mandar", en la medida en que su labor está reconocida y apoyada por la guerrilla. La mayoría de veces los Comités intentan, en primer lugar, mediar entre los involucrados; si no lo logran buscan una fórmula de acuerdo que agrade a las partes involucradas; si así tampoco entonces toman una decisión. En algunos casos los Comités desisten en la segunda etapa, es decir, cuando no logran poner de acuerdo a las partes con sus propuestas, entonces es cuando el problema se va para la guerrilla.

Pero cuando se toma una decisión, ¿es respetada por las partes? Se presentan tres casos: el primero es que efectivamente se cumple lo que el Comité ordenó. El segundo es que una parte, o las dos partes, no quedan conformes y se dirigen a la guerrilla. Allí la guerrilla puede: revisar el caso y tomar una decisión sobre éste (que puede ser la misma que el Comité u otra diferente), o "regañar" a quienes se le acercan argumentando que aquello que dice el Comité "debe respetarse". El tercer caso es que los involucrados en un primer momento reconocen la decisión pero más adelante uno de ellos la incumple; allí la contraparte se dirige, o bien al Comité o directamente a la guerrilla, porque finalmente, cuando alguien no cumple lo que el Comité "manda", siempre llega a la guerrilla. Y allí la guerrilla revisa el caso y si apoya la decisión del Comité obliga a la contraparte a cumplir. Si lo hecho por el Comité fuese considerado una decisión "injusta" por la guerrilla, retoman el caso y lo resuelven "a su manera".

El debate acerca de si un Comité puede o no decidir presenta una variable amplitud de posiciones entre los campesinos; según la vereda se interpreta la cuestión. Cuando se 
asume que el trabajo de un Comité está acaparado por la guerrilla, se asume que lo dicho por el Comité es "ley". Pero como la guerrilla ha insistido que cuando el Comité no pueda arreglar "por las buenas" se lleva el caso donde ellos, también se asume que las partes no conciliadas pueden ir donde la guerrilla. Ambos casos pueden presentarse: se acata la decisión del Comité o se supera esa instancia para acudir a la guerrilla.

Si bien ya se han visto varios aspectos que configuran al Comité de Conciliación, la versión "oficial" sobre el proceder de un Comité dada por un presidente de Junta, El Pollo, da buena cuenta de cómo debe trabajar el Comité Conciliador y deja patente la contradicción entre el Comité obra como Juez, pues puede tomar decisiones que como resultado generan "un ganador" y "un perdedor". Por eso, consideró él, el Comité es la instancia más delicada de una Junta. Pero a continuación, en la misma entrevista se contradice porque da a entender que un Comité no puede decidir. Ello a razón de que la naciente "práctica" de los Comités, acaparada por la guerrilla, no ha establecido aun cuál de las dos posturas integrar al "proceso regularizado".

El Pollo: Un Comité no puede mandar porque por eso se llama "Comité Conciliador", porque el Comité no puede ser autoritario, porque mal sería de un Comité, dos o tres personas, decir "usted haga esto, esto y esto" No, porque entonces seguro que los deja más en problemas. Y entonces no se llamaría un Comité Conciliador, me imagino que para conciliar las dos personas quedan de acuerdo en cómo son las cosas.

Pero desgraciadamente en casos extremos para poder arreglar un problema hay uno que pierde, si no nunca se va a poder arreglar un problema. Y usted sabe que va a haber un descontento, pero tiene que haber un perdedor. Entonces el Comité hace eso, y si por ejemplo evalúa un daño, lo primero que tiene que hacer un Comité no es tanto dejarse llevar por una sola versión. Cuando sucede algo yo siempre les digo a los del Comité que averigüen el problema, qué pasa con el problema de fulano y zutano. ¿Para qué? Para que no vayan a arreglar el problema sin antes haber averiguado por fuera. Porque es que las versiones son varias y uno no puede dejarse involucrar tanto de las partes implicadas en el problema, porque como le decía antes: "lo que pasa con fulano es esto, esto" y el otro dice lo mismo, y al final no se sabe quién tiene la razón.

Entonces la forma más fácil de saber cómo es el problema es averiguándose por otro lado, ¿para qué?, para ir más o menos empapado: "el problema con fulano y mengano es que a fulano le gusta ser cansón" y va y le dice. Y es que al valorar un daño se busca algo justo, algo imparcial. Si es un daño de ganado pues vamos a arreglar el problema y se dice "esto vale tanto, pero como ustedes son amigos pues dejémoslo en tanto, y partamos diferencias". Y si no se puede arreglar ese problema en el Comité Conciliador hay un coordinador, y el coordinador hace un acta. El acta tiene que hacerla arréglese o no se arregle el problema. Y si no se arregla el problema el acta la firma el coordinador, los otros conciliadores y las dos partes, constando que no se pudo arreglar el problema. Esa acta se hace llegar a manos del presidente de la Junta. Esa acta se hace llegar a la "oficina de Quejas y Reclamo. y entonces la guerrilla entra a arreglar el problema, si miran que el problema es de importancia. Es que hay gente que pelea por diez metros de linderos, "si porque fulano de tal me corrió la pica cinco metros" es un problema que en realidad da hasta pena ir a llevarle el problema a otro tipo, problema que entre los dos se puede arreglar. Esa es la función de un Comité.

En efecto existió en La Macarena un Oficina de Quejas y reclamos que funcionó a manera de una Inspección de Policía. Durante un tiempo fue reconocida la presencia de guerrilleros y 
guerrilleras que se encargarian de recibir las "apelaciones" como la presencia de la Oficina de Quejas y Reclamos. Con el tiempo, y hoy día, la idea de la oficina solo hace parte del recuerdo.

\section{El Comité por dentro.}

Cuando se eligen los directivos de una Junta, cada dos años, se elige el Comité Conciliador que lo componen tres personas. Cuando renuncia un miembro del Comité, en la reunión más próxima que esté programada en la vereda se elige otra persona que llene ese vacío. Por lo general son hombres maduros que hayan vivido un buen tiempo en la vereda, pero de vez en cuando (muy de vez en cuando) se sabe de jóvenes y mujeres que conforman estos Comités. La participación de las mujeres en las instancias comunitarias no solo se ha incrementado, sino que también ha mejorado con el tiempo. Sin olvidar que una de las fundadoras de la organización comunitaria fue doña Ana de Aza en los años 70, la marginalidad de las mujeres se ha superado con la activa participación de jóvenes y señoras en instancias comunitarias de todo nivel.

Hoy día hay una presidenta de Junta en la Julia, un caserío de reconocida importancia en la región (no es la única mujer que oficia como presidenta de junta, cabe aclarar), comités de mujeres en las Organizaciones Regionales, y representantes gremiales. La credibilidad de las personas que aspiran a ser parte de los Comités es de vital importancia. Aunque esto no se habla en una reunión, donde se califiquen abiertamente las cualidades de las personas, se sabe que la persona de un Comité debe ser alguien responsable, que no sea bebedora, cumplida en los negocios, que no tenga problemas con nadie, que sea seria, lleve una vida ejemplar y que lleve harto tiempo viviendo en la vereda.

Los mecanismos de trabajo de un Comité no están contemplados en ningún tipo de reglamentación, pero la costumbre y tradición han hecho que al ocurrir un conflicto en la vereda una de las partes, o todas, se dirijan al Presidente de Junta o directamente al Comité(a uno de sus miembros o al coordinador). Allí se da la primera versión de los hechos. El coordinador visita a los otros miembros del Comité y cuadran una fecha para visitar a los "emproblemados". Aquel día hablan con ellos, visitan los lugares que haya que inspeccionar y conciertan una cita entre el Comité y los implicados. Durante las visitas, las inspecciones y la reunión todos los miembros del Comité van explorando posibles fórmulas de arreglo con los afectados, aventuran hipótesis y hacen propuestas "al aire". La amplitud del discurso aborda las leyes que se conocen, la discusión se remonta a lo que es justo para una u otra persona, y sobre ello se vuelven a discutir las leyes y las posibles medidas a tomar. Con el acompañamiento del Comité, el problema se soluciona, la mayor parte de veces, inmediatamente, a través de una conciliación. Si no se da la conciliación el Comité se reúne, si no ese día, después en "esos días", no más de una semana y discuten cual puede ser la solución. Aunque los tiempos no están reglamentados, tanto el Comité (al igual que la guerrilla) resuelven los conflictos rápidamente.

Los miembros del Comité discuten, exploran todas las posibilidades y "miran las soluciones". Según me contaron en el Socorro, por lo general logran llegar a un consenso sobre la solución más adecuada. En caso de no lograrlo se van a votación y gana la propuesta que tenga dos votos. En casos extraordinarios, en problemas importantes que involucra a varias personas de la vereda, el caso es llevado a una asamblea de la Junta. De igual forma se procede en el extraño caso que el Comité no llegue a un acuerdo. Es de anotar que si aquello que el Comité decide como correcto es aceptado por las partes o es apoyado por la guerrilla, en caso que la decisión haya modificado una ley (me refiero a las leyes campesinas, esas normas consuetudinarias de viejísima tradición) o no trabaje sobre ninguna sino que actúe plenamente en equidad, la acción del Comité es perfectamente una fuente de 
derecho. Es decir, y en pesada jerga académica, crea un antecedente jurisprudencial. Tales antecedentes son claves e importantes para posteriores trabajos, pues en ocasiones para prevenir o solucionar casos, un Comité de Conciliación puede recordar la ocasión en que "otro Comité arregló asi”", sea o no de la vereda, lo que corrobora que se trata de un derecho consuetudinario.

Las discusiones del Comité, claro está, no son a puerta cerrada. En la vereda se hace vox populi el problema y en todas las casas siempre hay algo que decir sobre el tema, un vecino por el cual tomar partido y una fórmula de arreglo preferida. Por lo tanto los miembros del Comité discuten sus posiciones en su hogar, con los trabajadores, con la persona que se encuentran en el camino, el domingo en el pueblo con gente de la vereda que pregunta " $¿ y$ cómo van a hacer con eso? Porque yo pienso que...". El presidente de Junta, cuando está al tanto de lo que hacen, también tiene algo que decir, aunque valga la aclaración: el Comité es autónomo y solo supedita su actuar y sus decisiones a las bases fundamentales del derecho consuetudinario; el Comité escucha a todo el mundo pero nadie puede dirigir sus actividades, ni siquiera la guerrilla, porque podrian perder toda legitimidad. Finalmente llega el día en que proponen la fórmula de arreglo y reúnen a los implicados y les comentan. Si ha sido una decisión difícil, aquella que da como "perdedor" a alguno de los afectados, la decisión se comunica a cada uno de ellos aparte.

En algunos casos los conflictos se llevan a las asambleas de la Junta para que "la comunidad decida" sin que medie el Comité de Conciliación. De igual forma en ocasiones la guerrilla remite la solución de ciertos conflictos a las comunidades. Son tan diversos los conflictos que han llegado a las asambleas de la vereda que es imposible decir cuáles son los problemas que competen, para su solución, a la vereda en general. El caso del violador que antes he mencionado, por ejemplo, según don Plínio llegó a manos de la vereda porque "...si el caso es grave, lo menos que ya es de gravedad y que de pronto no tiene solución, se lo dejan a la comunidad pa' que decida". La interpretación de Don Plinio contradice el supuesto orden jurídico que impera en La Macarena, porque los problemas "graves" son competencia de la guerrilla. Pero así pasó en aquella ocasión, así lo recuerdan en el Socorro y así hace suponer que el orden jurídico de La Macarena es un orden de relativo alcance, porque como se ve en este, y otros casos, los supuestos procedimentales no son tan rígidos ni consecuentes con la "normatividad vigente", poniendo en entredicho la idea de un estricto "proceso regularizado".

\section{El contexto social de la resolución de conflictos.}

En ocasiones cuando los Comités de Conciliación intervienen en un conflicto levantan actas. Por lo general cuando se logra llegar a una conciliación basta la palabra de los involucrados para cumplirla y respetarla, así que levantar un acta no es primordial, pero aún así empieza a hacerse costumbre. No es aún una práctica generalizada llevar siempre actas ni remitirse a los antecedentes del trabajo del Comité o la guerrilla en la toma de decisiones. Pero el recuerdo permanece y constante de aquello que alguna vez hizo la guerrilla y/o el Comité, y la manera como lo hicieron, es un referente importante a la hora de discutir fórmulas de arreglo, "investigaciones" o hipótesis sobre los casos, sean estos llevados por el Comité o la guerrilla. Las actas cumplen un efecto de oficialización, definida por Bourdieu como la manera de identificar un efecto de homologación. "Homologar, etimológicamente, es asegurar que se dice la misma cosa cuando se dicen las mismas palabras, es transformar un esquema práctico en un código de tipo lingüístico de tipo jurídico... La publicación es una operación que oficializa, por lo tanto legaliza, porque implica la divulgación, el descubrimiento frente a todos y la homologación, el consenso de todos sobre la cosa descubierta". (Bourdieu, 2000) 
El mismo análisis cabe para la costumbre de algunos frentes guerrilleros de dejar por escrito las normas de convivencia y dejarlas en sitios públicos o consignarlas en sus revistas.

Cuando el Comité "decide" algo y los implicados reconocen la decisión como una fórmula de arreglo favorable para sus intereses, a veces se hace un acta que firman las partes comprometiéndose a respetar lo acordado. Cuando no se acepta lo que el Comité propone, y el paso que sigue es ir con la guerrilla, la escritura de un acta es obligatoria pues alli se deja constancia del problema, las fórmulas de arreglo propuestas por el Comité y la decisión y argumentos de los afectados frente a ellas. Las actas se escriben en un papel común, a mano y con la típica redacción y estilo de los campesinos de la región, en su mayoría con poca escolaridad pero con mucho ingenio para describir lugares y situaciones, sin el menor asomo de jerga jurídica. Aunque claro, para hacer un poco más oficial el asunto y reconocerle la importancia y seriedad que le merece, varias actas son llevadas al pueblo para que sean pasadas "a computador", y a varias se les pone el sello de la Junta. Entre las muchas cosas que este "proceso regularizado" no contempla, están los contenidos de las actas. Así como la retórica, la materia de las actas es de variable amplitud y depende de cada Comité qué consignar en ellas. Se deja una copia con el secretario de la Junta y se da otra a cada uno de los implicados.

Al terminar el trabajo del Comité, en toda la vereda se discute sobre el desarrollo de los hechos y la solución del conflicto. El dictamen del Comité pasa al escrutinio público y representa mucho para ganar la confianza de la comunidad, pues si lo hecho por el Comité no es satisfactorio para la gente de la vereda, más adelante puede pasar que la validez de una decisión tomada por el Comité no cuente con respaldo. Es muy probable que cualquier problema pase directamente a la guerrilla hasta que las personas del Comité no renuncien.

El apoyo que una comunidad da al Comité se traduce en el respeto y confianza que éste genera en la vereda. La experiencia, antecedentes y efectividad del Comité es la garantía de legitimidad y reconocimiento. Las decisiones y acciones del Comité nunca pasan desapercibidas en una vereda, donde todo ello es comentado: en las casas, los tajos (cultivos de coca), las vaquerias, las reuniones, etc. Es precisamente desde estos espacios que ha calado, aunque muy timidamente, las bondades y ventajas de arreglar problemas con el Comité sin que se haya recurrido a la guerrilla. Es claro que los Comités de Conciliación se enfrentan con situaciones donde la solución implica que uno de los envueltos en el conflicto sacrifique intereses y "pierda", pero por lo menos se agotan instancias de convencimiento sobre un amplio margen de argumentación donde se define, redefine y adapta la noción de "lo justo". El Comité asume en ocasiones aquello que El Pollo llamaba "la posición de un juez", teniendo en cuenta que un Comité "briega para poner de acuerdo a las personas", según comentaba Don Plínio.

Con la guerrilla es distinto, pues aunque de un comandante a otro cambian las cosas, es una tendencia general arreglar los problemas de forma expedita, rápida y en todo caso de forma autoritaria. La guerrilla manda a secas, aunque respete el sentido de lo justo, se ciña a las leyes campesinas, y su acción por tanto sea reconocida como legal. Su participación entraña, casi siempre, que como resultado haya un ganador y un perdedor. Esa dinámica trae problemas, no solo para la guerrilla, pues puede hacerle perder simpatias, sino que puede fracturar a las comunidades, generar conflictos, rivalidades y rencores no solo entre los implicados sino también entre los amigos del perdedor o del ganador. Si antes se han agotado instancias de discusión, de retórica, de argumentación, cuando la guerrilla "manda" a hacer algo no es tan problemático, porque por lo menos queda en el ambiente que "si la gente no arreglo fue porque no quisieron". Como decía, esta situación se hace evidente 
para muchos campesinos que empiezan a ver en los Comités una forma "justa" de arreglar problemas "a lo bien". Sobre esto conversé alguna vez con Doña Támara y Don Plínio.

Don Plinio: Es que yo digo una cosa, que mientras la gente busque el Comité Conciliador para el arreglo se arregla mucho mejor. La gente afloja en un problema, así sea el que sea; porque si uno va a llegar de berraco a dárselas de "aquí tienen que arreglar como yo digo" no hay caso. Es que uno es un mediador que únicamente se pone de acuerdo con las partes y asi se arreglan los problemas. Y queda más contenta la gente, de pronto porque ambos se pusieron de acuerdo y dijeron: "bueno, vamos a arreglar nosotros aqui así" $y$ no que es que llegue la guerrilla y diga: "no es que aqui hacen esto y es que lo hacen..."

Doña Támara: $Y$ es que así se sienten humillados...

Don Plinio: ...entonces va a quedar uno más mal. En cambio si el Comité llega y dice: "necesitamos que las dos partes del problema se reúnan y dialoguen a ver como nosotros analizamos el problema"; y ahí ellos se ponen a dialogar y uno después les dice: "vea, la salida es esta y esta así." Entonces la gente va a quedar más conforme, que se arreglaron a lo bien, sin necesidad de amenazas ni nada arreglaron el problema.

\section{Conclusiones.}

La Justicia Local de La Macarena se sustenta en una serie de criterios normativos de origen campesino que encuentran su mejor expresión en la manera como los Comités de Conciliación trabajan para resolver conflictos de carácter comunitario. La legitimidad de los Comités se ha construido, por un lado, por la delegación y reconocimiento que ha hecho la guerrilla para su trabajo, que ofrece certeza a los campesinos en que el trabajo del Comité está respaldado por la autoridad política que en la zona rural han conocido desde hace décadas. En segundo lugar, esta legitimidad se constituye a partir del reconocimiento de miembros de las comunidades cuando ven el Comité como una institución que puede arreglar de mejor forma un problema que la guerrilla. O por lo menos, que lo puede arreglar tan bien como lo haría la guerrilla.

El reto que esta situación representa para las comunidades de La Macarena es muy grande, porque la autonomía que han ganado en este sentido encuentra resistencias que han de vencerse, no solo de parte de algunos frentes y comandantes que han insistido en monopolizar la solución de conflictos, sino mayoritariamente entre comunidades campesinas que aún no confian en los Comités y no se acostumbran a recurrir ante "unos vecinos" para arreglar problemas. Lo anterior porque el imaginario de poder sobre la ley para hacer respetar lo justo, depende mucho en el reconocimiento de la fuerza de la guerrilla y validez de autoridad que se le confiere.

¿Qué pasará con los Comités y la Justicia Local una vez se empiece la dejación de armas por parte de la Guerrilla? No solo dudo que los comités desaparezcan, pues la justicia oficial aún tiene serios problemas de alcance y efectividad, sino porque estas instancias comunitarias han ganado el respaldo y legitimidad en amplias capas de la población regional. Así mismo, la Justicia Local -como he propuesto- ha sido un escenario comunitario para la materialización de autonomías políticas, fuente de liderazgo social y espacio para el reforzamiento de los lazos sociales.

Es por eso que ante la perspectiva de un acuerdo de paz y la entrada en marcha de un proceso de transición, la Justicia Local debe ser un apartado de especial atención de las organizaciones comunitarias y los actores involucrados en el diseño del post conflicto. Los 
Comités deben ser protegidos de las pretensiones de cooptación de parte del derecho oficial y su discurso tal vez pueda ser reconstituido de tal forma que no requieran una segunda instancia armada para la toma definitiva de decisiones.

Y quizás sea esta una de las contradicciones más interesantes para discutir en a región durante la transición: tras la dejación de las armas de parte de la guerrilla y con la legitimidad política regional afianzada en las organizaciones comunitarias, ¿cómo superar la necesidad de una segunda instancia con capacidad coercitiva? ¿Cómo reforzar y extender la legitimidad existente de la justicia comunitaria para que no necesite de un cuerpo armado? 


\section{Referencias Bibliográficas.}

Agnew, J., \& Oslender, U. (Julio-Diciembre de 2010). Territorialidades superpuestas, soberania en disputa: Lecciones empíricas desde América Látina. Tabula Rasa, 13, 191213. Obtenido de http://www.scielo.org.co/scielo.php?script=sci_arttext\&pid=S1794$24892010000200008 \& \operatorname{lng}=$ en\&tlng=es.

Bourdieu, P. (2000). Cosas dichas. Barcelona: Gedisa.

Caguán Vive. (14 de Mayo de 2009). Caguán vive. Recuperado el 11 de Noviembre de 2014, de www.youtube.com/user/caguanvive: https://www.youtube.com/ watch?v=u2WgCNS7wJ8.

Caracol. (13 de Enero de 2002). CARACOL. Recuperado el 1 de Junio de 2014, de Caracol. com: http://www.caracol.com.co/noticias/cronologia-del-proceso-de-paz-entre-elgobierno-y-las-farc/20020113/nota/104818.aspx.

Centro Nacional de Memoria Histórica CNMH. (2014). Centro de memoria. Obtenido de centromemoria.gov.co: http://centromemoria.gov.co/wp-content/uploads/2014/11/ El_Caguan.pdf.

Cubides, F. (1989). La Macarena: Reserva biológica de la humanidad. La Macarena: Universidad Nacional de Colombia.

Cubides, F. (1998). Crónica de un breve trabajo de campo en el área de despeje. Análisis politico, 1-16. Obtenido de http://fcubides.tripod.com/sitebuildercontent/ sitebuilderfiles/cronicaareadespeje.pdf.

Cubides, F. (2005). Algunas consideraciones sobre los procesos de paz fallidos en Colombia (O de cómo inventar caisas creíbles). 3er Seminario internacional de investigación, la investigación en ciencias sociales y Estudios politicos "Negociación, discusión racional y acuerdos”. Bogotá: Universidad Nacional de Colombia. Obtenido de http://fcubides. tripod.com/sitebuildercontent/sitebuilderfiles/fallidanegocia.pdf.

Cubides, F., \& Dominguez, C. (1999). Desplazados, migraciones internas y reestructuraciones territoriales. Bogotá: Observatorio socio-politico y cultural - Universidad Nacional de Colombia.

Forero, S. (2014). Estudio sobre el papel articulados de la Marcha Patriótica y el Congreso de los Pueblos en la movilización social por la paz en Colombia (2010-2013). Bogotá: Universidad del Rosario. Obtenido de http://repository.urosario.edu.co/bitstream/ handle / 10336/8849/1020758644\%20-\%202014.pdf?sequence=6\&isAllowed=y.

Fundación Paz y Reconciliación. (2014). Informe Caracterización del movimiento social Marcha Patriótica. Ensayo que recoge las diferentes perspectivas que tienen los lideres nacionales y regionales del movimiento social de Marcha Patriótica sobre su interés en participar en politica y la expectativa sobre los diálogos de La Habana. Bogotá.

González, F. (Mayo- Agosto de 2002). Colombia entre la guerra y la paz. Aproximación a una lectura cgeopolitica de la violencia colombiana. Revista Venezolana de Economía y Ciencias Sociales, 8(2), 13-49. 
Hart, M. (1992). El concepto del derecho. Buenos Aires: Abeledo Perrot.

Leal, F. (2006). dossier - 4 años del gobierno Uribe: balance y perspectivas. Análisis Politico, 3-30. Obtenido de http://www.ideaspaz.org/tools/download/50659.

Marín, K. (2014). La victimización horizontal y los retos de la justicia transicional en el posconflicto colombiano. Una propuesta metodológica. Cultura Investigativa, 108-123. Obtenido de http://www.researchgate.net/publication/271204287_La_victimizacin_ horizontal_y_los_retos_de_la_justicia_transicional_en_el_post_conflicto_colombiano._ Una_propuesta_metodolgica.

Marín, K. (2015). Entre vecinos: Retos de la justicia transicional a nivel local. El caso de la Sierra de la Macarena, Colombia. El Ágora USB.

Molano, A. (1999). Siguiendo el corte. Bogotá: El Ancora Editores.

Noticias del Llano. (7 de Mayo de 2013). Noticias del Llano. Obtenido de http://www. noticiasdelllano.com/noticias/por-matanza-en-la-macarena-hombre-es-condenado-a40-anos-de-prision.

Ramírez, E., González, E., \& Espinosa, N. (2014). Justicia comunitaria en los llanos del Yarí, Caquetña. La justicia, ¿Al margen de qué? Ciudad Paz-ando, 5(2), 127-148. Obtenido de http://revistaciudadpazando.udistrital.edu.co/documentos/revistas/revistadiez/ Articulo9_V5N2.pdf.

Revista Semana. (23 de Julio de 2010). Revista Semana. Recuperado el 01 de Junio de 2014, de http://www.semana.com/nacion/conflicto-armado/articulo/centenarescadaveres-nombre-cementerio-la-macarena/119648-3.

Ribon, M. (2014). Estudio de caso. La Marcha Patriótica como movimiento social y politico: Análisis de la naturaleza de un actor en construcción a partir de su accionar y sus reivindicaciones (2010-2012). Bogotá: Universidad del Rosario. Obtenido de http:// repository.urosario.edu.co/bitstream/handle/10336/8930/1018439641-2014. pdf? sequence $=4 \&$ is Allowed $=y$.

Ruiz, D. (2003). Campesinos entre la selva, invasores de reservas. Tabúla Rasa, 183-210.

Sousa Santos, B. (1991). El estado, derecho y luchas sociales. Bogotá: ILSA Instituto Latinoamericano de Servicios Legales Alternativos.

Tercer Canal. (28 de Julio de 2010). Tercer Canal. Recuperado el 12 de Junio de 2014, de https://www.youtube.com/watch?v=6kiinnSBypg.

TIEMPO, E. (30 de Agosto de 2007). Periódico El Tiempo. Recuperado el 01 de Junio de 2014, de eltiempo.com: http://www.eltiempo.com/archivo/documento/CMS-3700814.

Vázquez, T. (2014). El papel del conflicto armado en la construcción y diferenciación territorial de la región de "El Caguán", Amazonía occidental colombiana. El Ágora USB, 14(1), 147-175. 
Vera, S. (2006). El derecho: Una construcción social. Un estudio de caso sobre las FARCEP y la región del Sumapaz desde la microsociología del Derecho propuesta por George Gurvitch. Bogotá: IEPRI.

Wolkmer, A. (2003). Pluralismo jurídico: nuevo marco emancipatorio en América Latina. En: Un debate sobre los estudios jurídico críticos. Mauricio García $V$ \& César A. Rodríguez (Eds.) Derecho y sociedad en América Latina: Un debate sobre los es. Bogotá: ILSA.

\section{Nota:}

${ }^{1}$ Este artículo se enmarca en la investigación "Justicia comunitaria como iniciativa de paz en un escenario de post-conflicto", financiada por la Universidad de San Buenaventura. El artículo expone apartes de mi Tesis de Sociología "A la otra orilla del río: la relación de los campesinos y la guerrilla en La Macarena". 
